\title{
Personal journal blogs as manifest internal conversation toward self-innovation: A semiotic phenomenological analysis
}

\author{
Conversa interna manifesta como autoinovação \\ nos diários pessoais em blogs: uma análise \\ fenomenológico semiótica
}

\author{
Daniela BENITES ${ }^{1}$ \\ Gustavo GAUER ${ }^{1}$ \\ William Barbosa GOMES'
}

\begin{abstract}
This work is a semiotic phenomenological approach of writing in personal journal blogs to define and verify their potential as continuous and sustained movement toward personal change or self-innovation. The analysis juxtaposes, by quantitative and qualitative methods, chronological self-referential text data (semiotics) with the meaning of internal conversation disclosed in discourse (phenomenology). We take a specific blog domain for posts from random bloggers that would present self-referent terms as "I feel", "I think", "I believe", "my life", etc. Then we selected those posts with dense self-descriptions and expression of disparate personal thoughts and feelings. Approximately 150 posts were analyzed, resulting in a final sample of 12 homogeneous posts from a heterogeneous group of bloggers, nine females and three males, all native English speakers. We conclude that personal blog texts help convey psychological well-being through dialogical self-clarification, facilitate the emergence of new perspectives or self-actualizing, and can lead to self-innovation.
\end{abstract}

Keywords: Blogs; Inner speech; Self-deliberation; Self-innovation.

\section{Resumo}

O presente trabalho recorre à fenomenologia semiótica para analisar diários pessoais em blogs com o objetivo de definir e verificar suas potencialidades como movimento contínuo e sustentado para mudanças pessoais e autoinovação. A análise justapõe, por métodos quanti e qualitativos, dados cronológicos e linguísticos de textos autorreferenciados (semiótica) com o sentido de conversas internas reveladas em discurso (fenomenologia). Foi tomado um domínio especifico para postagens aleatórias de blogueiros que apresentassem termos autorreferentes, como "eu sinto" "eu penso", "eu acredito", "minha vida" etc. A partir disso, foram selecionadas postagens com autodescrições densas e

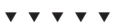

${ }^{1}$ Universidade Federal do Rio Grande do Sul, Laboratório de Fenomenologia Experimental e Cognição, Programa de Pós-Graduação em Psicologia. R. Ramiro Barcelos, 2600, Sala 123, 90035-003, Porto Alegre, RS, Brasil. Correspondência para/Correspondence to: W.B. GOMES. E-mail: <gomesw@ufrgs.br>. 
díspares de pensamentos e sentimentos pessoais. Foram analisadas, aproximadamente, 150 postagens heterogêneas das quais retirou-se 12 postagens homogêneas, sendo 9 escritas por mulheres e 3 por homens, todos falantes nativos da língua inglesa. Concluiu-se que o texto de blog pessoal enseja bem-estar psicológico por meio de autoclarificações dialógicas, além de facilitar a emergência de novas perspectivas ou autoatualização podendo, assim, conduzir à autoinovação.

Palavras-chave: Blogs; Conversa interna; Autodeliberação; Autoinovação.

Personal journal blogs are interactive e-writings maintained through specific authoring tool and published on the World Wide Web in a reverse chronological sequence of dated entries (Herring, Scheidt, Kouper, \& Wright, 2006). They are used mainly to express personal views and commentaries (Nardi, Diane, Schiano, Gumbrecht, \& Swartz, 2004), and are often linked to a profile that may disclose personal information about its author (Kumar, Novak, Raghavan, \& Tomkins, 2004; Misoch, 2015). Blogging may be characterized as an outlet for thoughts and feelings with patently emotional content; a way to explore obsessive and passionate issues. It could maintain, train, or even advance communicational skills. Generally, the motivation for personal blogging varies from "recording life" to "keeping family and friends updated". However, personal blogs general applying and expressing entail identifiable psychological constructs such as self, identity, social interaction, and relationships (Bronstein, 2013a). Displaying of such personal information is favored because blogs allow for greater anonymity, reduced importance of physical appearance, gating features for relationship development, and for greater control over interactions (Bronstein, 2013b; Hollenbaugh 2010). For this analysis, we leave aside the negative social effects of blogging such as bullying (Juvonen \& Gross, 2008), and risk factors such as involvement with antisocial peers, negative affect, drug and alcohol abuse, and problematic behavior in school (Anderson-Butcher et al., 2010). The focus will be the transformative potential of blogs' self- expressions as a public movement toward self-innovation.

In this present study we assume that in human science classical literature are always reference to eidetic frame and empirical evidence. Thus, four theories have been chosen as background 432 for this study: Hermans (2004) theory of the dialogical self; Archer's (2003), theory of internal conversation; Wiley's (1994) theory of the semiotic self; and Lanigan's (1992) quadrilateral discourse model. The supporting literature will be mentioned anywhere in the text, where relevant.

Archer (2003) defined self-innovation as the unfolding of thought into the stances of speaking and listening that is internal conversation. In that sense, thought would be the dialogue between distinct temporal phases of the self, and self-innovation would be obtained by means of such internal conversation.

Wiley $(1994,2016)$ defined human selfhood as a self-producing semiotic process occurring through internal conversation formed by inter- and intra-personal dialogues and entailing a self-other reflexive loop. Thus, internal conversation occurs among three temporal aspects, parts, roles, or agencies of the self: the past "Me", the present "I" and the future "You". In a dialogical relationship, the (present) "I" speaks to the (future) "You" about (past) "Myself". Only the present self or "I" can speak, while the "You" and "Me" can only listen and be spoken to (Wiley, 1994).

Hermans and Hermans-Konopka (2010), in a constructionist approach, defined self as a narrative dialogical process endowed with dynamically related personal positions. Such positions are sequentially given voice during dialogue, thus allowing contents to emerge while negotiating meaning through narratives and dialogues over time.

Lanigan (1992) stated that a semiotic phenomenological perspective of the self involves not just three components, but a system of four terms, as founded in the work of Merleau-Ponty (1945/2012). The four component system is a derivation of the dyadic relation between le même et l'autre discussed in modern French philosophy 
(Descombes, 1979). According to Lanigan, there are two possible translations: 'self versus other' and 'same versus different'. These four terms compose a quadrilateral of discourse in which 'self' is 'same' and 'other' is 'different' or conversely in all the quadratic combinations that are possible.

Wiley (1994) mentioned some sources for empirical research on audible externalization of internal conversation that could be captured in texts: little children talking alone, ordinary people who talk out loud to themselves, and people speaking during sleep. Archer (2003) used introspective or retrospective reports as data on internal conversation. DeSouza, DaSilveira, and Gomes (2008) used thinking aloud in the resolution of a problem. However, personal journal blogs present texts almost exclusively expressing detailed selfinformation, and thus may be regarded as valid external manifestations of a lessened internal conversation. They expose the tension among the sediment discourse (past self or 'Me') versus an authentic speech (present self or ' $I$ '), in a search for novel meanings within a social self (future self or 'You'). These temporal aspects of the self are dialogically expressed in specific texts with many disparate self-descriptions.

Our specific aims for this study were: 1) pointing out the semiotic structure of blog posts as a communicational interplay between temporal aspects of the Self; and 2) describing and thematizing self-related contents as inner experience manifested in internal conversation. We expected: 1) to justify the use of blog texts as an empirical source of data for the study of internal conversation and as an eidetic differentiation between the trialogue and quadrilateral dialogical models (the first pointing out the reversal relation between self and other, and the second the perceived contrast between same and different); 2) to explore the role of blogging in conveying psychological well-being through dialogical selfclarification and the emergence of new positions or self-innovation; and 3) to reaffirm the dialogical character of the inner experience that in privacy manifests itself by internal conversation. Notice that the main interest of this study is a theoretic look at empirical models to examine externalized modes of internal conversation, technically self-innovation points out to personal deliberation, independently of its possible values or directions.

\section{Method}

\section{Instruments and Procedures}

We mined a specific blog domain for posts from random bloggers that would present selfreferent terms such as "I feel", "I think", "I believe", "my life", etc. Then, we selected those posts with dense self-descriptions and expression of disparate personal thoughts and feelings. This process, mining plus qualitative selection, was performed until we achieved a sample size capable of offering a descriptive picture of the expressive patterns through semiotic content analysis. Approximately 150 posts were analyzed, resulting in a final sample of 12 homogeneous posts from a heterogeneous group of bloggers, nine female and three male, all native English speakers. This collected material constituted the parameter posts for our analysis. Only eight of these selected bloggers published age information, which ranged between 18 and 32 years-old (Average - $A=22.87$; Standard Deviation - $S D=5.33$ ). These posts contained up to 350 words $(A=246.41 ; S D=60.51)$. We blindly retrieved five posts immediately preceding and succeeding each of these 12 parameter posts previously selected, obtaining a longitudinal sample with 120 posts. The study was approved by the university ethical committee. Names and pseudonyms of participants were kept confidential, and quotes from the blogs were substituted by sentences with the same meaning and structure, in order to avoid tracking of the original data sources through search engines.

The blogs in this sample were active from two to nine years $(A=5.16 ; S D=2.58)$, contained 63 to 4.044 texts $(A=987.5 ; S D=1258.08)$, and were linked to 0 to 25 communities $(A=5.75$; $S D=7.44$ ), which are groups of bloggers that have a common interest in specific topics. The authors had from 0 to 185 friends $(A=48.25 ; S D=66.99$, 
were friends of 1 to 103 bloggers $(A=29.66$; $S D=38.79)$; and listed from 0 to 149 interests $(A=27.09 ; S D=42.92)$, as an outline of their personal characteristics.

Semiotic phenomenological analysis (Lanigan, 1994) is defined as a conjunction between human intension and extension. Intension is a logical term that characterizes a particular narrative in a manifest internal conversation as disclosive discourse (the parameter post). Extension is a logical term that characterizes a common structure here represented by the chronological self-referential text data (the preceding and succeeding posts). The personal journal blogs are taken as phenomenological process of individual meanings, and the text data as a semiotic structure.

The analysis follows the three semiotic phenomenological stages (description, reduction, and interpretation), each stage being constituted by the same three stages and so on (Gomes, 2007; Lanigan, 1988, 2013). First, we distinguished and punctuated particular themes (syntagmatic axis elements) and the general structure (paradigmatic axis elements) of the 12 parameter posts. The guiding question was: what characterizes selfinnovation? Second, we provided a longitudinal account for the 120 posts, formed by five posts respectively preceding and following each selfinnovation parameter to punctuate the syntagmatic chain that characterizes the moving towards and from self-innovation. The guiding question was: what are the changes in the blog posts that preceded and succeeded each parameter post? Finally, we integrated and contrasted the two first stages in a phenomenological interpretation.

\section{Results}

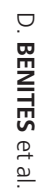

\section{First stage of analysis: Semiotic phenomenological punctuation of the parameter posts}

In the first stage, we have treated the parameter post collection as a structure, and taken

434 the syntagmatic and paradigmatic combinatory relations to guide our reading. Syntagmatic relations refer to elements that might combine in a sequence, and paradigmatic relations refer to elements that can replace each other by opposition (Suassure, 1916/1986). Thus, we started distinguishing each parameter post by title to point out the main concerns and define the syntagmatic axis that is the post as a particular narrative. The title was composed using the posts' (P) native words: P1) "No one wants to be around me"; P2) "I do not understand my feelings"; P3) "Dealing with new situations"; P4) "Lost between my computer and myself"; P5) "Trapped between two worlds"; P6) "Trying to betray my happiness"; P7) "All the puzzle pieces have started making sense in my life"; P8) "Throwing everything that is me out the window"; P9) "Random thoughts that make no sense"; P10) "I know what I want and I'm going to get it"; P11) "I feel positive about my art when I'm away from the studio"; and P12) "I've been really consistent (again) about physical exercise lately".

Comparing the parameter posts, we were able to punctuate and name six sequential events (paradigmatic axis): setting, description, conflict, openness, confusion, and conclusion. Following, we define each event. The examples (Italic font) refer to post 8 . The description with emphasis on exchanging positions is related to Hermans' theory (Hermans, 2004, 2015).

Setting is an affirmation or simple expression, usually stated early in the text, of a dominant or ongoing position perceivable in the present by the author: "I'm trying to grow up. I'm trying to get out of the whole that is my life. I'm trying to throw everything that is me out the window".

Description is sequence or list of different and sometimes opposing positions that, in the dialogical flow, are moving to or looking for a new position: "I've known this, but my pot is constantly boiling over. I've been holding back and flipping out so many times late". It refers to a kind of discomfort and a certain effort to try something different.

Conflict is an opposition of two positions and/or by the expression of uncertainty or doubt about them: "Until I finish with myself I can't be 
better. I'm so worthless". Note that a previous discomfort was localized ("finish with myself"), a hope seems to disappear at the horizon ("I can't be better") and suffered feeling was expressed ("I'm so worthless").

Openness is a direct question to the exterior or to others about what the author should do or think. It characterizes the blogger in a learning condition: "Until / destroy myself I can't be better".

Confusion is a kind of narrative pause that usually includes the communication of not knowing the motive for the act of writing and not knowing about the overall expressed content: "I don't even know why I'm writing this". This can be interpreted as strangeness into the void left by the clash between self-positions.

Conclusion is an affirmative phrase that presents a new action or thought summarizing and/ or resolving previous contents. It is the selfinnovation that may be transformed in deliberation: "I'm going to feel better about myself".

These events could be interpreted as constituting parts of a narrative progress that is accessed when the syntagmatic elements move among the paradigmatic levels (parallel sequential events or synchronic parts). Paradigmatic axis indicates a qualitative correlational hierarchy that constitutes the semiotic system or referential context (Lanigan, 1992).

The examples presented in Table 1 illustrate the writing style that characterized the 12 parameter posts. The two examples describe a critical existential event that questions a present situation by contrasting it with previous experiences. Thus, the narrative implies both a stable and active part, able to posit and consider comparisons of itself

Table 1

The two axes of selection and combination in semiotic systems: The syntagmatic and paradigmatic relations in the parameter posts

\begin{tabular}{|c|c|c|}
\hline \multirow{5}{*}{4} & & Syntagmatic Axis \\
\hline & $\begin{array}{l}\text { EVENTS } \\
\text { (Reduction) }\end{array}$ & $\begin{array}{l}\text { POST (narrative: phenomenological description) } \\
\text { (Blog post 4: Lost between my computer and myself) }\end{array}$ \\
\hline & Setting & $\begin{array}{l}\text { The deeper I get into my rather... unique... career, the more I feel like I am becoming like the machines I work } \\
\text { with. }\end{array}$ \\
\hline & Description & The funny thing is, my online identity means more to me these days than my real life self. \\
\hline & Conflict & I suppose my online self is more of my identity than my real world self, odd as that sounds. \\
\hline \multirow{8}{*}{ 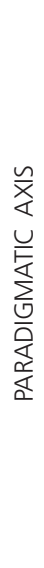 } & Confusion & $\begin{array}{l}\text { I'm not sure how to put this into words, honestly. Is it addiction if I feel like I have to have something to make my } \\
\text { identity complete? }\end{array}$ \\
\hline & Conclusion & $\begin{array}{l}\text { My physical body is just the meat behind the keyboard that is the machinery that supports the identity, which I } \\
\text { view as "me". }\end{array}$ \\
\hline & Events & $\begin{array}{l}\text { POST } \\
\text { (Blog post 9: Random thoughts that make no sense) }\end{array}$ \\
\hline & Setting & Sometimes I think about everything I've gone through and wonder: What if? \\
\hline & Description & $\begin{array}{l}\text { What if I never lasted almost a year in a relationship with you? Would I be an improved person? Or would end up } \\
\text { exactly the same? }\end{array}$ \\
\hline & Conflict & It's stuff like this that keeps me up at night. \\
\hline & Setting & I finally graduated, only to be hurled into a world that doesn't make sense to me. \\
\hline & Description & People who will walk on others just to make individual gains. \\
\hline \multirow{4}{*}{$\mathbf{V}$} & Confusion & This post is mostly formed by random thoughts that make no sense. \\
\hline & Setting & There are nights where it turns to be really lonely. \\
\hline & Openness & But it is a condition that I am learning to deal with. \\
\hline & Conclusion & And I am glad with myself as a person. And very happy with how my life has turned out. \\
\hline
\end{tabular}


between previous and current states of affairs, promoting adjustments that can bring, simultaneously, a sense of easy and discomfort. This movement is interpreted by Archer (2010) as simultaneity and alternation in the internal conversation. The self narratives were a kind of retrospect, a synthesis and an analysis referent to personal events from an immediate past with sights on the future.

Figure 1 offers a semiotic phenomenological interpretation, by simulating the flow of speech in a gradual emergence of communicational events. It combines all elements from the trialogue model (The 'l' talks to 'You' about 'Me') (Wiley, 1994, 2016) and the quadrilateral model- self versus other/same versus different (Lanigan, 1992, 2013). The events setting and conclusion comprised the starting and ending points of self-innovation flow, when the self (I)/same (Me) moves towards an absent content and intentionally meets a complementary informational level, which are the aspects: other (Myself, personal) and different (You, public). In the same act, self/ same and other/different come into clash. It is manifested as conflict and/or confusion. Aspects relating both self (I) and same (Me) can be described, acknowledging the existence of aspects that comprise both other (Myself) and different (You). This moving may incite openness. The conversation may take advantage of the openness to continue

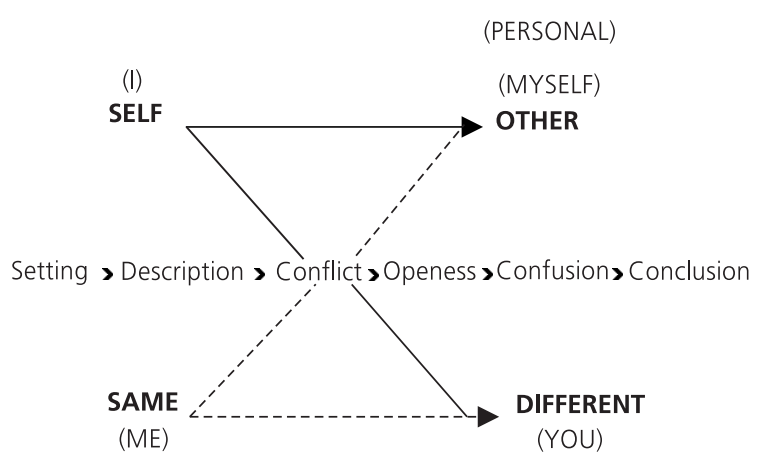

(PUBLIC)

Figure 1.Communicational flow combining the trialogue (I - Me - You) and the quadrilateral model (Self vs. Other; Same vs. Different).

Note: The interesting aspect of the quadrilateral model is to 436 distinguish 'Same' (Me) from 'Myself' (Me). the exploration and clarify an innovation, that is, a kind of personal deliberation (Archer, 2010), which is the same as self-actualizing for Gendlin (1962), or authentic speech for Merleau-Ponty (1945/2012). So, this speech chain describes the reflexivity in action as self-innovation, where conclusion is the resultant deliberation. Also, we could have the opposite, a deadlocked internal conversation (Joireman, Parrott, \& Hammersla, 2002) that would be characterized not by self-innovation or actualizing, but by sedimented speech or rumination.

\section{Second stage of analysis: Semiotic phenomenological punctuation of the sequence of posts}

The second analysis looked at the sequence of posts leading up to the self-innovation and those that followed. At this point the study shifts from a choice of context (qualitative inquiry) to a context of choice (Lanigan, 1992, 2013) given by a quantitative estimation of the preceding and succeeding types (semiotic punctuation) in the sequence of posts. The sequence ranged from short and direct communication with one's blog audience to extensive references to inner contents and personal deliberation. The extracted types express each post's functional role longitudinally - within the blog and in relation to the self-innovation posts that served as reference for their sampling. Each entry was defined as mainly expressing types of proximity communication, named: contact, monitoring, self-narrative, or self-innovation.

Contact texts exposed self-related inner and/ or outer information to the audience in a short and direct way. They reported specific perceptions about oneself, others, and/or the external world in commentaries or short opinions and evaluations. Those texts did not present context or description of motivations or any specifications of their contents. They were simple forms of establishing contact with the outer world. In the long term, this category might express a way to expand the author's inner dialogical landscape by acknowledging the existence of a flexible audience, one that can be 
quickly accessed through any kind of dialogue, including short informational exchanges.

Monitoring occurred when the authors briefly described self-related inner and/or outer aspects, and evaluated those aspects according to feelings and emotions in a sequence of brief exposures. The authors perceived and exposed what was happening in their inner and/or outer environments and valued if the contents were in agreement with their views and emotions. These posts revealed the role of attention in collecting information that may be important when deciding upon future thoughts and/or actions. The perceptions were followed by evaluations. If the evaluations were related to each other or in a sequence, it would bring forth a self-narrative text (next category). However, if there were no evaluations, the text would be an extended communication (in between the first and second categories).

Self-narrative texts exposed self-referred inner and outer aspects followed by the description of the related feelings, emotions, and opinions, i.e., followed by a set of self-evaluations. Descriptions of outer aspects were secondary, and self-evaluations were the main focus of attention. The author explored his/her inner states linking self-evaluations through comparisons and re-evaluations. Despite the dense personal content, this category did not underlie the formation of a constructive and comprehensive overall self-evaluation (selfinnovation). In some of the self-narrative posts, authors addressed feeling the lack of an overall selfunderstanding and questioned why they did not understand their inner contents in simpler ways. This category of texts might bring together unrelated positions, which favors a further appearance of an overall comprehensive position, as it occurs in self-innovation texts.

Figure 2 evidences the posts' syntagmatic chain as demarcated by a paradigmatic configuration. The messages' types along the five columns that precede the parameter indicate a movement from contact, which is direct communication, to self-narrative, that is, an immersion in self- evaluation. In contrast, the message' types across the five columns that follow the parameter brings a movement from self-monitoring to self-innovation. A close look at each preceding columns reveals a contact prominence at column -5 , self-narrative messages at columns $-4,-3$ and -2 , and selfinnovation at columns -1 . The same trend occurs in the following four columns with monitoring being the most prominent, as if the blogger was attending to his/her new deliberations. This significant trend of higher monitoring after self-innovation can be illustrated by a simple nonparametric measure, Wilcoxon Signed Ranks Test: $z=-2.032 ; p=<0.05$. Self-innovation messages will appear again in the 5 column, maybe announcing a new development for self-innovation.

The second stage of analysis supported the idea that the index choice for blog searches was not arbitrary. The indexes (factual contiguity) "I feel", "I think", "I believe", "my life" and similar self-referent terms were able to spot self-innovation posts during the automated phase of the sampling procedure. The marked change of self-expression after self-innovation characterizes self-innovation posts as candidate parameters for studies on self, identity, psychotherapy, clinical philosophy, and dialogical markers.

\section{Third stage of analysis: Semiotic phenomenological interpretation}

Our analyses took 12 parameter posts as a phenomenological description that was reduced to six events (setting, description, conflict, openness, confusion, and conclusion). Each expressive event found to compose self-innovation posts may be regarded as informal recurrent patterns leading to: linguistic reduction, construction of self-conscious qualia, and self-innovation as already (Neuman \& Nave, 2010). The juxtaposition of these informational patterns supports the emergence of self-actualization by semiosis, or the production of meaning (Van den Hoven, 2015). Actualization of self-content through dialogical acts and self-innovation could allow an optimized planning and completion of personal intentions in the course of time, as recognized by Hermans (2004) in his dialogical self theory. 


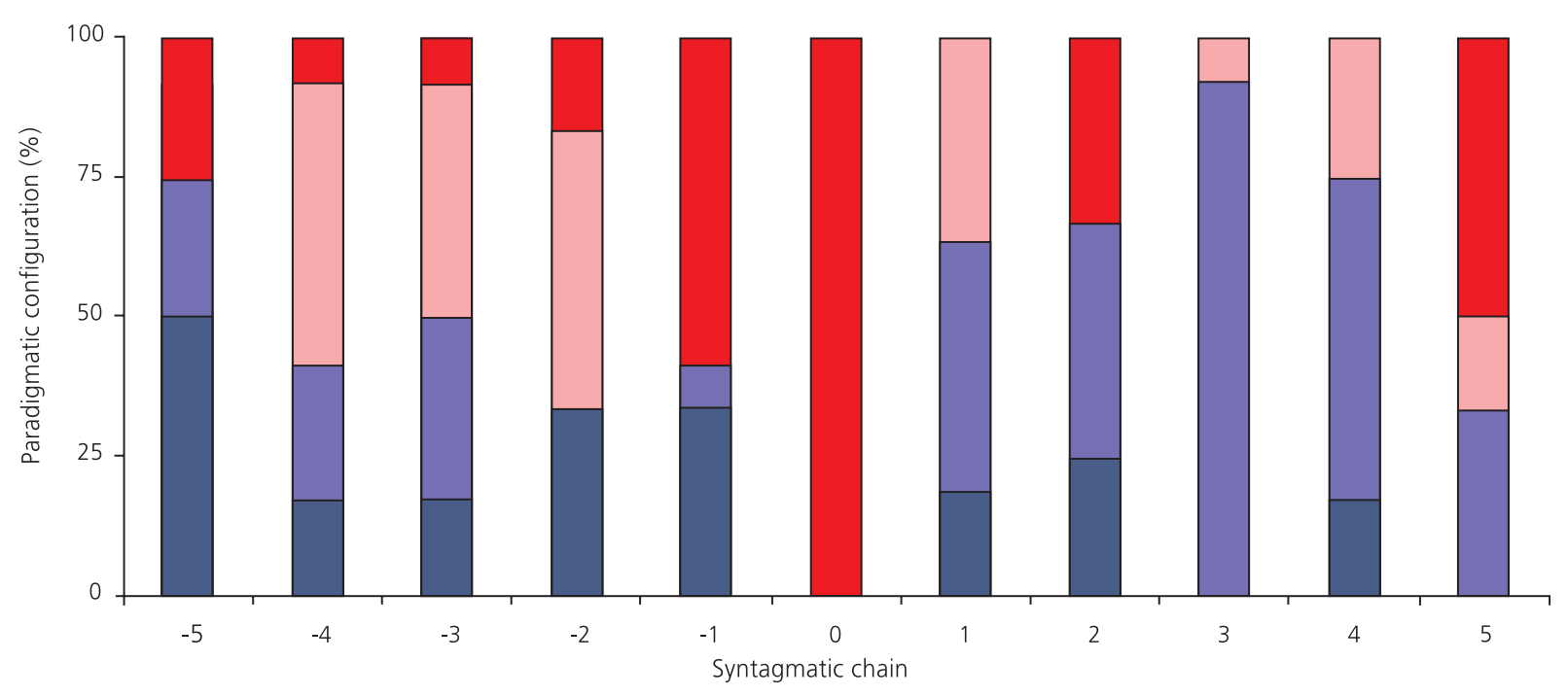

Self-innovation $\square$ Self-narrative

$\square$ Monitoring

$\square$ Contact

Figure 2. Personal public expression of self-innovation.

Note: Sequence of posts' types before and after the self-innovation parameter post (at $x=0$ ). Each post was classified according to its main message (bottom legend). Distributions of message types preceding the parameter indicate a movement from contact $(x=-5)$, which is direct communication, to self-narrative $(x=-4,-3,-2)$, that is, an immersion in self-evaluation, and to self-innovation ( $x=-1,0 ; 0$ is the selected parameter). The five columns after the parameter evidence a movement from self-monitoring $(x=1,2,3,4)$ to, again, some self-innovation $(x=5)$. This significant trend of higher monitoring after selfinnovation can be illustrated by a simple nonparametric measure, Wilcoxon Signed Ranks Test: $z=-2.032 ; p=<0.05$.

The events openness, confusion and conclusion appear as constituting an essential structure for a manifested self-innovation. Openness events seem to be encouraged by blogs, which are described as promoting a sense of security, community, and control over personal information (McKenna \& Bargh, 2000). Confusion events may be linked to the emotional demands and risks of self-innovation, while conclusion events may bring relief and a feeling of effectiveness as indicated in dialogical self theory (Hermans, 2004). Together, these events can be interpreted as forming the medium connecting previous and subsequent expressive dynamics. In the theoretical description of the semiotic self (Wiley, 1994) they combine the informational flow from the immediate I-present concerned about the Me-past looking at the Youfuture. In this model, the chain of the three communicational events - openness, confusion and conclusion -, are the semiotic elements that promote temporal understanding and homeostasis across meaning creation and self-change in the blogging

438 process.
The great surprise in this study came from the preceding and succeeding parameter post analyses. Theoretically, the results were expected, but the force that came from this empirical demonstration is new and very important. We know that self-innovation is not a stable episode, nor collapsed in it. For example, in the confusion the sign presented itself tied to openness that requires explanation and clarification about the renewed self. However, as demonstrated in the second analysis, its object is translated into the self-monitoring descriptions brought to the blog after the parameter. So, self-monitoring is a result from the confusion that arises during self-innovation, securing the renewed self by taking a close look at its actions and thoughts. This configuration defines self as an overall unlimited semiotic experience producing homeostasis and changes (transitions) not in well-defined, but throughout a process that involves the types found in the self-innovation posts.

Self-innovation posts are special types of expression that bind long temporal scales, previous 
and subsequent self-positions, through unpredictable emergent short-lived structures, named openness, confusion and conclusion. The model adds a semiotic basis to theories regarding a dynamic self (Kelso, 1995) and offers thematic and communication types as possible concepts for analysis of change in dynamic and recordable settings, such as blogs and psychotherapy.

Self-change is a core concept in human development and should become a pragmatic tool for evaluating mental health, which is the capacity of one's mind to generate novel and actualize meanings of life. Communication of self-innovation in blogs has exposed a minimal semiotic structure for creation, adjustment, and expression of a renewed self. Self-change was interpreted as being bridged and structured by openness, confusion, and conclusion.

\section{Conclusion}

The present analysis about personal journal blogs opens a rich empirical avenue to review the natural unfolding of thought and internal conversation as ongoing reflexivity. Personal journal blogs are not a verbatim transcription of internal conversation as in experiments that include thinking aloud in the resolution of a problem (DeSouza et al., 2008). They could be described as retrospective reports in the same style as the interviews used in Archer's studies (Archer, 2003). The posts bring, with extreme vivacity, a personal drama as an inner dialogue which connects to a judgment, leading to a partial conclusion or an imminent action. In that sense, this conception is very close to Colapietro's (1989, p.117) definition of reflexivity as internal conversation:

Internal reflection does not reside in taking stock of what we have already thought or in attempting to view what we are presently thinking; it resides in engaging in an inner dialogue - indeed an inner drama -, and in judging the outcome of that dialogue or drama.
Self-innovation in this context refers to the small steps among different possible positions in the understanding and handling of a given situation or moment in life. The self-referent indexes were useful in the identification of self-innovative posts, which were those expressing the imminent need to resolve a personal drama. This conclusion is based on the comparison between the two analyses performed: parameter versus sequential posts. The first analysis concentrated on the expressive events that specified meaning as novelty, highlighting the semiotic trialogue that starts with a speaking critical self interrogating a "Me" as a summation of the past, personalized sediment and socialized deposit on the perspective of a better future. This personal confrontation touches directly on the controversial issue of human agency with implications to the agentive internalism versus externalism debate (Sugarman \& Sokol, 2012).

Before we exam the implications for human agency, it is advisable to return to the parameter posts and review how they were combined from the terms used in the current literature on inner dialogue. They may be present at three explanatory levels. The first one indicates a theoretical line of reasoning with descriptors for a possible movement, generally defined as positions (Hermans \& HermansKonopka, 2010), meaning from where it comes and to where it goes. If we substitute the term initial position for initial content it is easy to understand that it refers to memories or personal sedimentation (Peirce, 1958), all of them contaminated or derived from the socialized deposit (Mead, 1934/1974). Looking to the future, these contents become perspectives and obviously the propositional qualities of these perspectives would indicate the possible outcome of these personal plots. However, this first level of theoretical specification recognizes the dialogical movement from one position to another, but does not clarify the movement itself from the divided self: the one that talks and the one that listens.

The second level departs from a differentiation between basic instances that constitute the dialogue and could be represented by Wiley's temporal phases of the self. Wiley (1994) described them as 
the communicative hexad, that is, the speaker communicating to the listener by semiotic triads (sign-interpretant-object) in a linear manner. The communicative hexad reveals the reversible relation between speaking and listening, or the phenomenology of expression and perception (Lanigan, 1992). If we connect this semiotic chain with syntagmatic and paradigmatic axes, we may enrich these perspectives by improving the reversible shifts among the axes. This second level of explication clarifies the ongoing chain of meaning and the instances that function as actors or characters (the temporal phases of the self).

The third level of explication point out the movement from an apparent split self towards selfinnovation, that is, the reversion between self and other, or same versus different (the quadrilateral model). The juxtaposition of the parameter and sequence posts distinguished two semiotic structures: 1) the new meaning emergence (openness, confusion, and conclusion), here recognized as self-innovation (the first analysis); and 2) the process toward self-innovation (contact, monitoring, self-narrative), here recognized as selfmonitoring (the second analysis). This combination explains reflexivity or self-innovation as a personal understanding turned upon itself by distinguishing: 1) a human evolutionary function, the capability of generating signs and to express them; from 2) a human cultural function, the sensibility to specify signs and to create or assimilate culture. So, the first condition is ahistorical and the second historical.

Self-innovation is the critical point for deliberation, that is, reflexivity or human agency. The hard problem is how to explain the relation between subjectivity (psychological processes, individuation, internalism) and objectivity (social structure, culture, externalism). This controversy entails a further development of this analysis, interpreting the semiotic structure in combination with the phenomenological content. The semiotic structure is interpreted here as the human capability for signification, that is, the intentional generation of signs in the sense that mind exists to think. In contrast, the phenomenological content is the intentional movement from experience to consciousness that we call reflexivity. Of course, culture is implicated in the two axes of this process; it can refine the capability for thinking and enrich what is to be thought.

Finally, the main point of this analysis was not the novelty of blogs as a technological fashion or the World Wide Web's communicative power, but to present them as an empirical source that may elucidate some theoretical aspects of internal conversation. The overall conclusion agrees with Perlovsky (2007a, 2007b), and Neuman and Nave (2010) in that blogs help to form novelty. However, it also suggests that they provide a stable tool for self-monitoring, which could foster self-innovation mainly by offering a high-dimensional mental space with lower costs, by offloading much of the already performed mental work into an easily accessible recording medium. Self-monitoring in blogs is, thus, an effective and personalized tool that health professionals might use to evaluate physical and psychological conditions and treatments when descriptive parameters are available and selfinnovation is desirable. Further studies may investigate how these and other expressive types appear in self-assessments before, during, and after psychological interventions, distinguishing normal and abnormal dynamics. Controlled samples may allow testing their presence, role, and necessary patterns during spontaneous and clinically supervised self-change.

\section{Contributors}

All authors contributed to the conception and design of the study, data analysis, and final draft of the article.

\section{References}

Archer, M. (2003). Structure, agency, and the internal conversation. Cambridge: Cambridge University Press.

Acher, M. (2010). Reflexivity. Sociopedia.isa. Retrieved July 9, 2011, from www.sagepub.net/isa/resources/ pdf/Reflexivity.pdf 
Anderson-Butcher, D., Lasseigne, A., Ball, A., Brzozowski, M., Lehnert, M., \& McCormick, B. L. (2010). Adolescent weblog use: Risky or protective? Child \& Adolescent Social Work Journal, 27(1), 63-77. http://dx.doi.org/ 10.1007/s10560-010-0193-x

Bronstein, J. (2013a). Personal blogs as online presences on the internet. Aslib Proceedings, 65(2), 161-181. http://dx.doi.org/10.1108/00012531311313989

Bronstein, J. (2013b). Being private in public: Information disclosure behaviour of Israeli bloggers. Information Research, 18(4). Retrieved May 15, 2014, from http:// www.informationr.net/ir/18-4/paper600.html\#.Vu WE5HOrKUk

Colapietro, V. (1989). Peirce's approach to the self: A semiotic perspective on human subjectivity. Albany: State University of New York Press.

Descombes, V. (1979). Le même et l'autre: Quarantecinq ans de philosophie française (1933-1978). Paris: Les Éditions de Minute. (Collection Critique).

DeSouza, M. L., DaSilveira, A., \& Gomes, W. B. (2008). Verbalized inner speech and the expressiveness of selfconsciousness. Qualitative Research in Psychology, 5(2), 154-170. http://dx.doi.org/10.1080/14780880 701734511

Gendlin, E. (1962). Experiencing and the creation of meaning. New York: Free Press.

Gomes, W. (2007). Distinção entre procedimentos técnico e lógico na análise fenomenológica. Revista da Abordagem Gestáltica, 23(2), 228-240.

Hermans, H. (2004). Introduction: The dialogical self in a global and digital age. Identity: An International Journal of Theory and Research, 4(4), 297-320.

Hermans, H. J. M. (2015). Dialogical self in a complex world: The need for bridging theories. Europe's Journal of Psychology, 11(1), 1-4. http://dx.doi.org/10.5964/ ejop.v11i1.917

Hermans, H., \& Hermans-Konopka, A. (2010). Dialogical self-theory: Positioning and counter-positioning in a globalizing society. Cambridge: Cambridge University Press.

Herring, S. C., Scheidt, L. A., Kouper, I., \& Wright, E. (2006). A longitudinal content analysis of weblogs: 2003-2004. In M. Tremayne (Ed.), Blogging, citizenship, and the future of media (pp.3-20). London: Routledge.

Hollenbaugh, E. E. (2010). Personal journal bloggers: Proles of disclosiveness. Computers in Human Behavior, 26(6), 1657-1666. http://dx.doi.org/10.1016/j.chb. 2010.06.014

Joireman, J., Parrott, L., \& Hammersla, J. (2002). Empathy and the self-absorption paradox: Support for the distinction between self-rumination and self-reflection. Self and Identity, 1(1), 53-65. http://dx.doi.org/10. $1080 / 152988602317232803$
Juvonen, J., \& Gross, E. F. (2008). Extending the school grounds? Bullying experiences in cyberspace. Journal of School Health, 78(9), 496-505. http://dx.doi.org/ 10.1111/j.1746-1561.2008.00335.x

Kelso, J. A. S. (1995). Dynamic Patterns: The self-organization of brain and behavior. Cambridge: MIT Press.

Kumar, R., Novak, J., Raghavan, P., \& Tomkins, A. (2004). Structure and evolution of blogspace. Communications of the ACM (Association for Computing Machinery), 47(12), 35-39. http://dx.doi.org/10.1145/1035134. 1035162

Lanigan, R. (1988). Phenomenology of communication: Merleau-Ponty's thematics in communicology and semiology. Pittsburgh: Duquesne University Press.

Lanigan, R. (1992). The human science of communicology. Pittsburgh: Duquesne University Press.

Lanigan, R. (1994). Capta versus data: Method and evidence in communicology. Human Studies, 17, 109-130.

Lanigan, R. (2013). Communicology and culturology: Semiotic phenomenological method in applied small group research. The Public Journal of Semiotics, 4(2), 71-103.

McKenna, K. Y. A., \& Bargh, J. A. (2000). Plan 9 from cyberspace: The implications of the internet for personality and social psychology. Personality and Social Psychological Review, 4(1), 57-75. http://dx. doi.org/10.1207/S15327957PSPR0401_6

Mead, G. H. (1974). Mind, self and society. Chicago: University of Chicago Press. (Original work published in 1934).

Merleau-Ponty, M. (2012). Phenomenology of perception. New York: Routledge. (Original work published in 1945).

Misoch, S. (2015). Stranger on the internet: Online selfdisclosure and the role of visual anonymity. Computers in Human Behavior, 48, 535-541. http://dx.doi.org/ 10.1016/j.chb.2015.02.027

Nardi, A., Diane J., Schiano, D. J., Gumbrecht, M., \& Swartz, L. (2004). Why we blog. Communications of the ACM (Association for Computing Machinery), 47(12), 41-46.

Neuman, Y., \& Nave, O. (2010). Why the brain needs language in order to be self-conscious. New Ideas in Psychology, 28(1), 37-48. http://dx.doi.org/10.1016/ j.newideapsych.2009.05.001

Peirce, C. S. (1958). Collected papers of C. S. Peirce (Vol. I-VIII). In C. Hartshorne, P. Weiss, \& A. Burks (Eds.). Cambridge: Harvard University Press.

Perlovsky, L. (2007a). Symbols: Integrated cognition and language. In R. Gudwin \& J. Queiroz (Eds.), Semiotics and intelligent systems development (pp.121-151). Hershey: Idea Group. 
Perlovsky, L. (2007b). Evolution of languages, consciousness, and cultures. IEEE Computational Intelligence Magazine, 2(3). 25-39. http://dx.doi.org/10.1109/M Cl.2007.385364

Suassure, F. (1986). Course in general linguistic. La Salle: Open Court. (Original work published in 1916).

Sugarman, J., \& Sokol, B. (2012). Human agency and development: An introduction and theoretical sketch. New ldeas in Psychology, 30(1), 1-14. http://dx.doi.org/ 1016/j.newideapsych.2010.03.001
Van den Hoven, P. (2015). Cognitive semiotics in argumentation: A theoretical exploration. Argumentation, 29(2), 157-176. http://dx.doi.org/10.1007/s10503014-9330-6

Wiley, N. (1994). The semiotic self. Chicago: The University of Chicago Press.

Wiley, N. (2016). Inner speech and the dialogical self. Philadelphia: Temple University Press.

Received: March 14, 2016

Approved: March 17, 2016 